\title{
New Zealand should intensify efforts to eliminate female genital mutilation by 2030: the views of women from communities that practice FGM/C
}

\author{
Ayan Said, Cath Conn, Shoba Nayar
}

\begin{abstract}
In 2016 UNICEF reported on the continuing scale and persistence of female genital mutilation globally, currently known as female genital mutilation/cutting (FGM/C), and the need to intensify efforts to eliminate the practice. New Zealand has made provision for communities in preventing FGM/C through legal and educational means. Yet, the challenge continues. The purpose of this paper, drawing on the voices of women from FGM/C practicing communities in New Zealand, is to consider areas where the health system can partner with affected communities to better help in preventing FGM/C. New Zealand needs to intensify efforts locally working hand-in-hand with refugee and migrant communities to promote open dialogue, counter stigma, and prevent the next generation for a life without $\operatorname{FGM}(C)$. In addition, training for key workers in culturally sensitive approaches is needed so that they can take better care of those who are living with FGM/C. New Zealand is a signatory to a number of international instruments and conventions that call for an end to FGM/C: such as the Universal Declaration of Human Rights and The Convention on the Rights of the Child (CRC), and more recently the Sustainable Development Goals (SDGs). As such, it has a responsibility to at least address the issue locally; and preferably provide an example of excellence globally so that FGM/C is eliminated rapidly.
\end{abstract}

Keywords: female circumcision, infibulation, young women, FGM, FGM/C, New Zealand, refugees

Ayan Said holds a Masters of Public Health from Auckland University of Technology and she is currently undertaking doctoral re search on sexual and reproductive health in Somalia. For correspondence: ayan.said@aut.ac.nz.

\section{Background}

Female genital mutilation/cutting $(\mathrm{FGM} / \mathrm{C})$ is defined as the partial or total removal, or injury, of external female genitalia for cultural or other non-medical reasons (WHO, 2016). It is a complex and multifaceted practice, deeply rooted in historical, cultural, social, and religious beliefs with unclear origins (Abdulcadir et al, 2011). It is often a rite of passage for girls entering womanhood and is commonly conducted between the age sof four and 13 years. The typology of FGM/C ranges from a small cut, usually on the clitoris, to full infibulation or narrowing of the vaginal opening (on a 1-4 scale of severity). The health risks associated vary according to severity of type. Globally FGM/C is often performed in unsterile conditions without the use of anaesthesia, and often in the absence of medical equipment. Cutting devices may include knives, razors, scissors, or sharpened rocks. This can lead to infection, haemorrhage and shock, as well as urinary and birthing complications in the longer term, and death (Jaeger et al, 2009). More recently, there has been medicalisation of the practice in some countries.

In 2016 UNICEF reported on the ongoing and significant scale and persistence of the practice of FGM /C and the need to intensify efforts to eliminate it (UNICEF, 2016). The purpose of this paper is to identify areas where the New Zealand health system can partner with affected communities, and, with the support of wider society, better help in preventing FGM/C locally. 
Furthermore, we call for New Zealand to be a global player in this vital issue by setting an example of excellence and advocating for more rapid change.

\section{Call for a local and global response to eliminating FGM/C}

Various initiatives have pre-dated the 2016 UNICEF call, including a 2012 milestone resolution of the UN General Assembly and the 2015 global agreement to initiate Sustainable Development Goals (SDGs), which included the target (Goal 5) of eliminating FGM/C by the year 2030 (UN, 2017). Although there has been an overall decline in FGM/C globally, as a result of a range of measures across health, education, community development, media, and legal sectors, the pace of decline is uneven and needs to be accelerated. In the context of population growth, without better progress, the number of girls and women globally undergoing FGM/C will rise significantly over the next 15 years (UNICEF, 2016). It is currently estimated that at least 200 million girls and women, from 30 countries, have undergone FGM/C, with the highest prevalence to be found in Somalia (UNICEF, 2016).

One positive development is that internationally, $61 \%$ of women and $63 \%$ of men in countries that practice FGM/C would like to see FGM/C eliminated (UNCEF, 2016). Research shows that if there is commitment and action from within communities that practice FGM/C then elimination can occur quickly (WHO, 2016). Eliminating FGM/C requires both primary prevention of the practice, with the backing of the relevant community, utilising a range of inter-sectoral mechanisms such as legal frameworks, education, and advocacy; and ongoing specialised care for those girls and women already affected (WHO, 2016).

Since the 1990s increased migration of refugee populations from areas that practice FGM/C brought the issue into New Zealanders' consciousness. Previously New Zealand accepted a quota of 750 refugees annually (which has now increased to 1000); of which a small number are from areas that practice FGM/C. Refugee categories include family re-unification migrants, asylum seekers, and emergency cases. Currently there are five refugee communities, and one migrant community, living in New Zealand which practice FGM/C: Egypt, Ethiopia, Somalia, Eritrea, Kurdistan (refugee communities) and Indonesia (migrant community). The current estimated population of adult women over 15 years from these communities is around 4,400 (New Zealand Census, 2013; Perumal, 2010). There are no accurate statistics for how many are living with FGM/C. Typically communities in which FGM/C is practiced, continue the tradition, to some extent, after migrating to New Zealand; but the scale of persistence is unknown. A significant challenge for those working on this issue is the regular influx of migrants from areas that practice FGM/C who have not experienced elimination programmes. As long as FGM/C practice continues within migrating communities, New Zealand will need to provide prevention measures and specialised care.

New Zealand has taken steps to prevent FGM /C through legal and educational means. The Crimes Act of 1961 (section 204A) was revised in 1996 making the excision of female genitalia for cultural or religious reasons illegal. A community based FGM/C Education Programme (FGMEP) was established in 1997 and it continues today (http://fgm.co.nz/). The programme develops educational resources for communities, schools, police and child protection workers, and provides information, training, and support for health professionals. The aim is that through education, communities will become more aware of the harm to health, allowing them to make informed decisions. The FGMEP is funded by the New Zealand Ministry of Health; however, community education is only available within the Auckland region. Given housing shortages, increasingly refugees, including those practicing FGM/C, are located to other parts of New Zealand, following on from their arrival in Auckland. This poses additional challenges for prevention and care around the country.

Specialised care for girls and women living with FGM/C is vital (WHO, 2016; WHO Guidelines). Guidelines for health care professionals dealing with antenatal, birth, and postnatal care for women with FGM/C are available. Yet, not all health professionals in New Zealand are sufficiently trained in the care of women with $\mathrm{FGM} / \mathrm{C}$, particularly during antenatal and postnatal periods, with the standard of care and awareness varying between clinics. A 1997 study, involving interviews with 88 Somali women indicated that nearly all of 
the respondents' health professionals knew little about this practice and there was a lack of communication between Lead Maternity Carers and women with FGM/C. By the time of the follow-up study (with 70 Somali women) in 2008 (Denholm and Powell, 2009), however, there had been an overall increase in FGM/C awareness among health professionals from $20 \%$ in 1997 to $80 \%$ in 2008 . The study showed that there was room for improvement, in that awareness did not necessarily translate to sensitive communication with women living with FGM/C, and there was considerable scope for more community education Denholm and Powell, 2009).

\section{Views of women from communities that practice FGM/C in New Zealand}

In the case of FGM/C social change relates to changing longstanding gender and sociocultural norms in diverse cultural contexts (WHO, 2016). The importance of conducting FGM/C elimination from within communities cannot be stressed enough, (WHO, 2016; Said, 2014; Said, 2015), especially given it is such a culturally bounded and highly sensitive subject. This makes it even more important to involve members of affected communities; as the se communities typically experience multiple vulnerabilities, and are not homogeneous having unique histories and cultural circumstances underpinning their FGM/C practice (Said, 2015; Mortensen, 2011).

Much of the published literature on FGM / C is generated from outside communities by those who do not engage in this practice. Given the deeply cultural and sensitive nature of the topic, this paper draws on data from an exploratory focus group conducted with four women educators working in Auckland (Auckland University of Technology Ethics approval was granted on 5 August 2014), one each from the Somali, Eritrean, Indonesian and Kurdish $\mathrm{FGM}(\mathrm{C})$ practicing communities (Said, 2015). Peer educators from within the community play an important role as change agents; they are committed themselves and understand the situation of their own communities. In the focus group women were asked questions about their experiences and views on the persistence of FGM/C and their suggested strategies for elimination. Women spoke of their own experience of FGM/C as well as those of other women and girls from their communities. Also, the lead author is a FGM/C campaigner, researcher, and educator from the New Zealand Somali community. The discussion below draws on her experiences, the views of women educators, and experience of conducting research with women from FGM/C communities in other parts of the world (Thuita, Conn, Wilson, 2016), against the backdrop of calls for intensified global efforts.

\section{Social, community and cultural sensitivity and FGM/C}

\section{Social benefits of FGM/C}

There was a lot of social pressures around it because I know for a fact that if I didn't have it done, then nobody would talk to me and I wouldn't be able to serve food to people, like nobody will respect me and I can't walk down the street without being abused. So there is a bit of social... social pressures or social identity as such like, it is what makes us who we are in terms of girls.

These words from one of the woman educators participating in the study illustrates the importance of the social benefits from FGM/C in a given cultural context. Being uncircumcised compromises the size of dowry a young woman could expect upon being married, undermines her identity as a woman and her personal credibility. Parents want to do what is best for their daughters, and they may perceive FGM/C as worth supporting to avoid being ostracised from their social group. Further, the issue of marriage does not go away when refugees migrate. The pool of suitable partners is small in the new country, and families may look to partners in the country of origin.

Any programme or initiative aimed at eliminating FGM/C must address the very powerful social factors acting to buttre ss the practice, and how elimination might occur without social damage (Berg and Denison, 2013; Berggren et al, 2006). The international community has 
been reluctant to engage fully with the issue of social benefits, perhaps because of a concern that it will be seen to dilute the elimination message. However, there is a need to acknowledge the social benefits and address those in dialogue with communities.

\section{Community silence on FGM/C}

They cut me and I wasn't allowed to talk about it, this is the first time I have shared this with anyone.

The taboo in talking about FGM/C is a common underlying factor in the persistence of the practice (Berg and Denison, 2013; Berggren, 2006). Normally women are not permitted to talk about their circumcision, even within the family. While the type of FGM/C experienced by women in New Zealand varied from a small cut to full infibulation, as did the culture in which it was done, the stories were similar in many ways. The women appreciated a rare opportunity to speak about the negative health impacts they and other women from their community, had endured, including infection and difficulty giving birth.

What emerges from this study is the importance of opportunities for dialogue and open discussion 'within' communities that engage in this practice and indeed families, as well as in the wider society. There is a need for 'talk' using all possible opportunities about the advantages and disadvantages of FGM/C; a need to promote intergenerational dialogue and more open dialogue within communities reflecting religious and ethnic differences beyond fear of legislation.

\section{Limited communication and cultural sensitivity skills amongst health workers}

When going to the hospital for my first like check-up and like even for me to talk to my midwife about what's wrong was very, very hard like it's not an easy thing to do because at that time you still don't know you're different, like you think you're the same like everyone else. So when I started seeing like nurses and doctors coming around and looking at me like a weird object it made me feel like I shouldn't be there. I didn't want to be looked at like I had done something wrong just because I wasn't normal in the Western society but it was very much normal back home. It make me feel like I couldn't go to hospital and get check-ups regularly, or talk to my midwife about it...

Women in the study spoke about experiences of utilising health services in New Zealand including the reactions of health professionals, problems in communication, and their own lack of knowledge about the implications for their health of FGM/C. They often learned more about their health situation under very uncomfortable circumstances. As the words above demonstrate, women living with FGM/C may easily be made to feel 'like a weird object' and this can only contribute further to a reluctance to discuss the issue. Women educators noted that in their country of origin health workers would be fully aware, and indeed often experienced $\mathrm{FGM}(\mathrm{C})$ themselves, providing a context of empathy which is not present in their new environment.

\section{Current strategies for the elimination of FGM/C-Legislation and education}

If everyone knows about the law...it says do this stuff...this one is against the punishment, may be some people they fear the punishment, so that might stop it.

[FGM/C is] Nobody's business, it's no big problem but now there is a bigger thing out there where there is the law, they can actually go to jail for doing this.

New Zealand, as with many other countries with communities that practice FGM/C, moved rapidly to put in place legislation to prevent its occurrence. Women agreed that legislative changes, along with education, were effective in preventing parents from having their daughters circumcised and may have acted in part as a reason why parents legitimately choose not to arrange for FGM(C) for their daughters in a cultural community in which this 
is treated as an accountable choice. However, by making the process illegal, without appropriate and supportive enforcement, it could potentially lead to more harm because people are forced into unregulated circumstances, such as taking their daughters overseas to be circumcised. Thus, legislation needs to be backed by appropriate support such as advocacy and education.

Education does work but I think education takes a long time to work.....education did help me to understand the risks involved with FGM/C.

It's hard to change what they're growing up...within two or three lessons...it takes time.

Education is a somewhat effective way of preventing FGM/C; although it requires persistence and time to change behaviour and attitudes. The women suggested that a transmission of ideas and attitudes might also be a feature to take into consideration when diaspora travelled to country of origin, thus expressing hope for a dissemination of FGM/C prevention messages. This would seem to be particularly important given the continuing movement of people from areas that practice FGM/C.

The international community has focused on FGM/C being a rights issue, and this is strongly reflected in the language of education and advocacy. However, the language of rights is not well understood by communities; whereas the language of health and wellbeing may be more relevant and better understood. Also, education and advocacy initiatives need to explore ways of minimising social harm to girls and women resulting from the change to a community that has stopped practicing FGM/C (Berg and Denison, 2013; Berggren, 2006).

\section{Recommendations}

The balance required between avoiding judgement about cultural norms, stigmatising people further, and intensifying efforts is critical for enhancing knowledge and sensitivity towards women from communities that practice FGM/C. Yet opportunities exist to maximise the support and expertise of women from within communities that practice FGM/C for the purpose of primary prevention and secondary care. We make some recommendations for elimination of FGM/C in New Zealand:

- The commitment and involvement of communities that practice FGM/C should be maximized beyond the role of peer educators, to include opportunities for women and men as champions, researchers and health professionals. Maximising this support, locally and globally in a non-judgemental way, involves sustained open dialogue within and between the different communities, as well as with wider society and health professionals (Jacoby and Smith, 2013; Isman et al, 2013).

- The New Zealand health system should intensify primary prevention using intersectoral approaches. Integrating FGM/C programmes with other women's services could be a more cost effective and appropriate solution with policies and programmes addressing FGM/C being inclusive, creative, and relevant to these populations (Denholm and Powell, 2009; Recchia and McGarry, 2017).

- Greater training and orientation for health workers is vital to ensure culturally informed and sensitive approaches. However, resources for initiatives are limited, and the challenge is made more difficult with the recent re-location of refugees around the country. Where heath care providers work with communities that practice FGM/C they should undertake training in the cultural context of FGM/C; clinical care of women with FGM/C (including deinfibulation care); and culturally appropriate sexual and reproductive health education. The World Health Organisation has recently published new guidelines on the management of health complications from FGM/C to update policy makers and health professional in this important matter (WHO guidelines). Training of health workers is even more important 
against the background of greater alienation and fear engendered by recent global terrorism and the socio-historical links between FGM/C and Islam.

- Addressing FGM/C and its specific gender health needs requires further research which adopts highly sensitive approaches and is conducted hand in hand with women and men from affected communities. Greater understanding is needed if appropriate action is to be taken in eliminating FGM/C (Abdulcadir, Rodriguez and Say, 2015).

- There are significant evidence gaps in four main areas: obstretric outcome and postpartum perineal education for women; de-infibulaiton outside pregnancy or labour; clitoral reconstruction; and training, skills and confidence of healthcare providers.

New Zealand is a signatory to a number of international instruments and conventions that call for an end to FGM/C: such as the Universal Declaration of Human Rights and The Convention on the Rights of the Child (CRC), and more recently the SDGs. As such, it has a responsibility to at least address the issue locally. Doing so is especially important in preventing the next generation of girls from being circumcised, whilst taking care of women who are living with FGM/C.

Acknowledgements to the participants of this research for sharing their thoughts, experiences and insights.

\section{References}

Abdulcadir J, Margairaz C, Boulvain M, Irion O. (2011). Care of women with female genital mutilation/cutting. Swiss Med Wkly. Jan 6:140:w13137.

Abdulcadir, J., Rodriguez, M. I., \& Say, L. (2015). Research gaps in the care of women with female genital mutilation: an analysis. BJOG: An International Journal of Obstetrics \& Gynaecology, 122(3), 294-303.

Berg R C, Denison E. (2013). A Tradition in Transition: Factors Perpetuating and Hindering the Continuance of Female Genital Mutilation/Cutting (FGM/C) Summarized in a Systematic Review. Health Care Women Int. 34(10): 837-859.

Berggren V, Musa Ahmed S, Hernlund Y, et al. (2006). Being victims or beneficiaries? Perspectives on female genital cutting and reinfibulation in Sudan. Afr J Reprod Health. 10(2): 24-36.

Denholm N, Powell M. (2009). Female genital mutilation 2008 health care survey report. FGM Education Programme, Auckland. November 2008.

Isman, E., Mahmoud Warsame, A., Johansson, A., Fried, S., \& Berggren, V. (2013). Midwives' experiences in providing care and counselling to women with female genital mutilation (FGM) related problems. Obstetrics and Gynecology International, 2013.

Jacoby, S. D., \& Smith, A. (2013). Increasing Certified Nurse-Midwives' Confidence in Managing the Obstetric Care of Women with Female Genital Mutilation/Cutting. Journal of Midwifery \& Women's Health, 58(4), 451-456.

Jaeger F, Caflisch M, Hohlfield P. (2009). Female genital mutilation and its prevention: a challenge for paediatricians. Euro J of Pediatr. 168(1):27-33.

Mortensen A. (2011). Public health system responsiveness to refugee groups in New Zealand: activation from the bottom up. Soc Pol J of New Zealand. 37:123-134. 
New Zealand population census (2013). Statistics New Zealand.

Perumal L. (2010). Health needs assessment of Middle Eastern, Latin American and African people living in the Auckland region. Auckland: Auckland District Health Board, 2010. Retrieved from

http://www.adhb.govt.nz/healthneeds/Document/MELAAHealthNeedsAssessment.pdf.

Recchia, N., \& McGarry, J. (2017). "Don't judge me": narratives of living with FGM. International Journal of Human Rights In Healthcare, 10(1), 4-13.

Said A. Stories and strategies of women living with female genital mutilation in Auckland communities. (2015). The sis, Auckland University of Technology, Auckland. Retrieved from http://aut.researchgateway.ac.nz/handle/10292/9198.

Said A, Simunovich P. Female Genital Mutilation Challenges in practice and policy within New Zealand.(2014). Department of Public Health, School of Public Health and Psychosocial Studies, AUT University. Retrieved from

http://www.aut.ac.nz/_data/assets/pdf_file/0003/513327/Said-and-Simunovich-finalbulletin-2014.pdf.

Thuita W, Conn C, Wilson K. (2016). The role of marginalised women in sanitation initiatives: Somali women in northern Kenya. Dev in Prac. 27(1):16-25.

UN (2017). Transforming our world - the 2030 agenda for sustainable development. United Nations, New York. Retrieved from https://sustainabledevelopment.un.org/content/documents/.

UNICEF (2016). Female genital mutilation/cutting: A global concern. UNICEF, New York, 2016. Retrieved from https://www.unicef.org/media/files/FGMC_2016 brochure final_UNICEF_SPREAD.pdf.

WHO guidelines on the management of health complications from female genital mutilation. World Health Organisation, Geneva. Retrieved from http://apps.who.int/iris/bitstream/10665/206437/1/9789241549646_eng.pdf.

WHO (2016). Female genital mutilation. Fact sheet, World Health Organization, Geneva, updated February 2016. Retrieved from http://who.int/mediacentre/factsheets/fs 241/en/. 